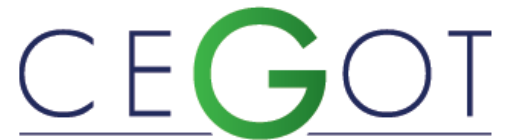

Centro de Estudos de Geografia e Ordenamento do Território
Geografia e Ordenamento do Território, Revista Eletrónica Centro de Estudos de Geografia e Ordenamento do Território http://cegot.org

Chagas, Marco

Universidade Federal do Amapá / Mestrado em

Desenvolvimento Regional

Rod. JK - Km 02 - Jardim Marco Zero - 68900-419, Macapá, Amapá - Brasil marco.chagas@uol.com.br

VASCONCELOS, ElizeU

Universidade Federal do Amapá / Mestrado em

Desenvolvimento Regional

Rod. JK - Km 02 - Jardim Marco Zero - 68900-419, Macapá, Amapá - Brasil

elizeucosta21@gmail.com

\title{
Licenciamento ambiental e desenvolvimento sustentável: possíveis integrações para territórios singulares na Amazônia brasileira
}

Environmental licensing and sustainable development: possible integrations for specific territories in Brazilian Amazon

Referência: Chagas, Marco; Vasconcelos, Elizeu (2019). Licenciamento ambiental e desenvolvimento sustentável: possíveis integrações para territórios singulares na Amazônia brasileira. Revista de Geografia e Ordenamento do Território (GOT), n. ${ }^{\circ}$ 17 (junho). Centro de Estudos de Geografia e Ordenamento do Território, p. 5-28, dx.doi.org/10.17127/got/2019.17.001

\section{RESUMO}

No Brasil, o licenciamento ambiental de alta complexidade apresenta-se como instrumento da política ambiental, capaz de contribuir com o desenvolvimento de territórios singulares submetidos a impactos significativos das atividades econômicas. Referida hipótese, entretanto, não se sustenta sem o fortalecimento de vínculos programáticos entre o licenciamento, o zoneamento e a avaliação ambiental estratégica. Este artigo discorre sobre a complementaridade desses instrumentos e sua aplicação para territórios singulares, que apresentam áreas protegidas e incipientes atividades econômicas passíveis de gerarem significativos impactos, como no caso do Amapá, estado localizado ao Norte da Amazônia brasileira.

Palavras-Chave: Amazônia Brasileira; Amapá; política ambiental; licenciamento ambiental; zoneamento; avaliação ambiental; desenvolvimento.

\section{ABSTRACT}

In Brazil, environmental licensing of high complexity is a tool of environmental policy able to contribute to the development of certain territories subject to significant impacts of economic enterprises. That hypothesis, however, does not stand without the strengthening of the programmatic bond between the licensing itself, the zoning and the strategic environmental evaluation. This article discusses the complementarity of these tools and the way they apply to specific territories, in which there are protected areas and inceptive economic activities that might bring about significant impacts, as in the case of Amapá, a state of the northern Brazilian Amazon. 
Keywords: Brazilian Amazon; Amapá; environmental policy; environmental licensing; zoning; environmental evaluation; development.

\section{Introdução}

No Brasil, o licenciamento ambiental é um dos mais importantes instrumentos da política ambiental à disposição do Estado, para gerenciar os impactos das atividades econômicas sobre a natureza e as pessoas. Recepcionado pela Constituição Federal brasileira de 1988 e pela Lei 6.938/81, que dispõe sobre a Política Nacional do Meio Ambiente (PNMA), o licenciamento ambiental encontra suas principais diretrizes vinculadas às Resoluções CONAMA 001/86, 237/97 e à Lei Complementar no 140/2011.

Para as atividades econômicas consideradas de significativo impacto ambiental ou de alta complexidade exige-se o licenciamento ambiental ancorado em avaliação de impactos, consubstanciada em procedimentos que devem considerar, prioritariamente, o processo de desenvolvimento, antes e depois da implantação da atividade, sem desconsiderar o conjunto de atividades econômicas preexistentes - impactos sinergéticos.

Para regiões industrializadas, os efeitos desenvolvimentistas de projetos econômicos se diluem pela individualidade do licenciamento ambiental e pelos ritos burocráticos vinculantes. Para outros contextos territoriais, pouco impactados pela atividade econômica, onde a decisão de implantar determinado projeto está associada à janela de oportunidades de mercado e a fatores associados à rigidez locacional de recursos naturais, o licenciamento ambiental gera expectativas desenvolvimentistas.

Entretanto, encontrar as conexões entre o licenciamento ambiental e o desenvolvimento, considerando escalas, vínculos normativos, categorias e significados de desenvolvimento, participação social, tomada de decisão política e melhoria contínua, requer esforços para além da mera condição de "entrave ou instrumento cartorial" a que o licenciamento vem sendo subjulgado e desqualificado como obstáculo ao desenvolvimento.

O caráter prévio do licenciamento ambiental cria vínculos e oportunidades de integrar outros instrumentos da política ambiental em favor do debate sobre desenvolvimento, diante da incipiente ou ausente cultura em planejamento estratégico no Brasil. Esse é o 
caso, por exemplo, do licenciamento ambiental, do Zoneamento Ecológico-Econômico (ZEE) e da Avaliação de Impacto Ambiental (AIA).

No Brasil, por força de lei, as potenciais atividades econômicas de determinada região devem ser identificadas e zoneadas, de modo a subsidiar a implantação de planos governamentais e privados. Nesse caso, o ZEE aproxima-se da AIA enquanto instrumentos de ordenamento do território e de avaliação prévia das consequências ambientais do desenvolvimento econômico, principalmente daquelas atividades que apresentam alguma condição de rigidez locacional, como no caso da mineração, hidrelétricas, petróleo, entre outras.

Entretanto, o licenciamento ambiental não se apropria desses instrumentos enquanto objeto de indução de ordenamento territorial e do desenvolvimento. O licenciamento ambiental torna-se, dessa forma, descontextualizado de uma efetiva gestão ambiental da região onde as atividades econômicas pretendem se instalar, tornando-se, de fato, mais uma "barreira verde" a ser transposta e check-list, da já exaustiva lista de exigências legais da administração pública para regularização de atividades econômicas.

Nesse ínterim, as avaliações ambientais que dão sustentação aos processos de licenciamento ambiental de atividades econômicas de significativo impacto ou de alta complexidade, em que pese sua evolução normativa e técnica, não se apresentam como suporte ao debate sobre o desenvolvimento ou mantêm-se desconectadas de uma sistemática de planejamento estratégico que possa antecipar consensos e dissensos sobre o impacto e o uso dos recursos naturais pelo mercado.

Esse parece um problema crônico do licenciamento ambiental, o que torna o instrumento um processo visto como entrave diante de janelas de oportunidades do mercado. Porém, existem encaminhamentos propositivos de que as avaliações ambientais que ancoram o licenciamento ambiental devem seguir diretrizes de planejamento estratégico e, como tal, projetar relações de causa e efeito decorrentes das intervenções no território, com impactos significativos previamente identificados e inseridos na agenda das políticas públicas de médio e longo prazo.

Este artigo, com base na análise de processos de licenciamento ambiental submetidos à avaliação de impacto ambiental e tendo o estado do Amapá como estudo de caso, discute 
os possíveis vínculos entre o licenciamento ambiental e o desenvolvimento; avalia perspectivas de planejamento estratégico e propõe encaminhamentos direcionados a maior eficiência e efetividade dos instrumentos da política ambiental aplicados em territórios singulares ou pouco impactados; propõe ainda reposicionar o licenciamento ambiental, quanto ao melhor aproveitamento das avaliações ambientais vinculadas ao ordenamento territorial e à consequente sinergia em favor do planejamento estratégico e do desenvolvimento sustentável.

\section{Metodologia}

$\mathrm{Na}$ parte normativa, rastrearam-se documentos que abordam os vínculos entre o licenciamento ambiental e o desenvolvimento, considerando a possibilidade de conexões e integração entre instrumentos da política ambiental, adoção de alternativas de planejamento estratégico e da melhoria contínua dos processos de participação social, diante da tomada de decisão sobre o uso dos recursos naturais (Figura 1).

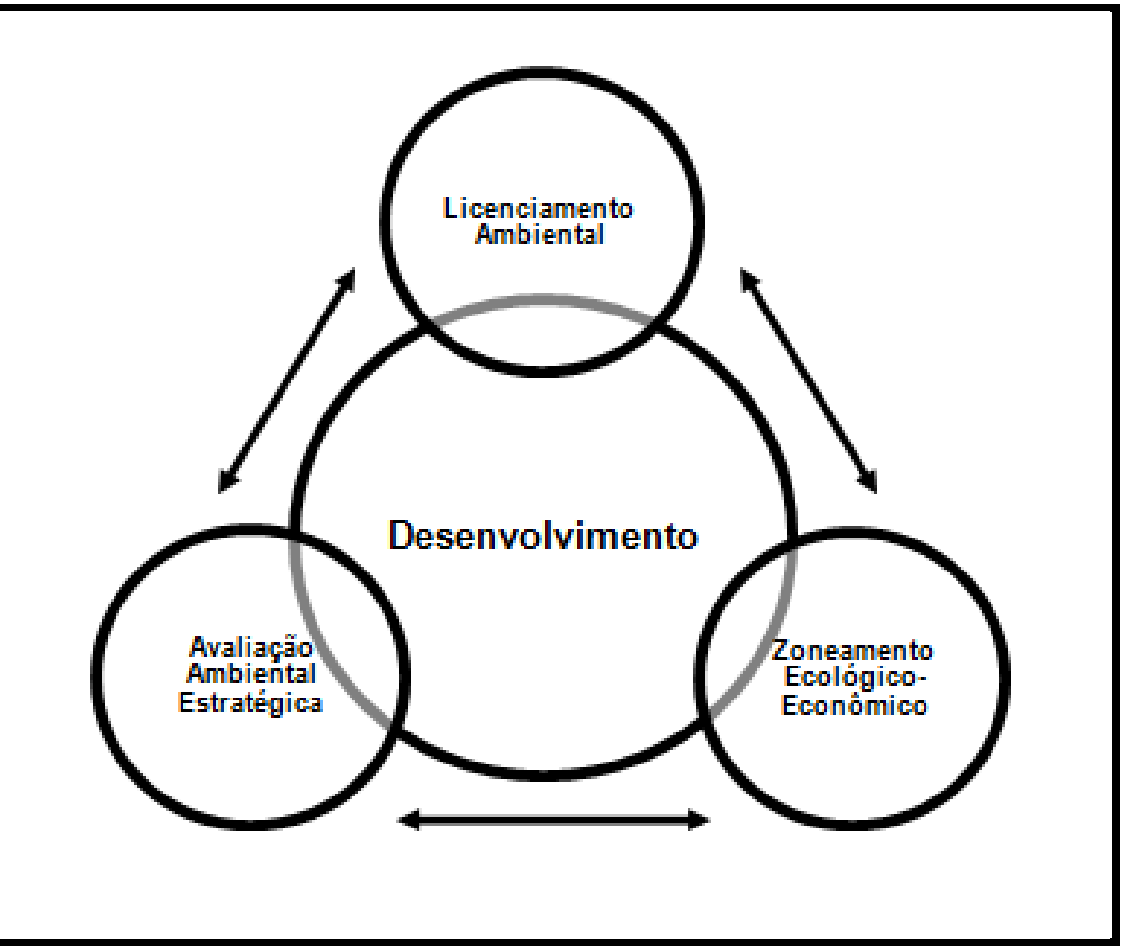

Figura 1 - Licenciamento, ZEE e AAE como contributo ao desenvolvimento Fonte: Elaboração dos autores. 
Com relação ao estado do Amapá, foram analisados os processos de licenciamento ambiental submetidos à EIA que constam na plataforma on-line do Instituto Brasileiro do Meio Ambiente e dos Recursos Naturais Não-Renováveis (IBAMA) e em arquivos do órgão estadual de meio ambiente do Amapá (não disponíveis on-line), de modo a possibilitar ampla representação do universo dos licenciamentos realizados.

A opção pelo Amapá como estudo de caso deve-se à singularidade do Estado Amazônico que se destaca pela representação territorial de áreas protegidas, incluindo (unidades de conservação e terras indígenas) (Figura 2). Nesse contexto, territórios singulares referem-se a estados amazônicos que apresentam extensas áreas protegidas e poucas atividades econômicas que demandam licenciamento ambiental de alta complexidade.

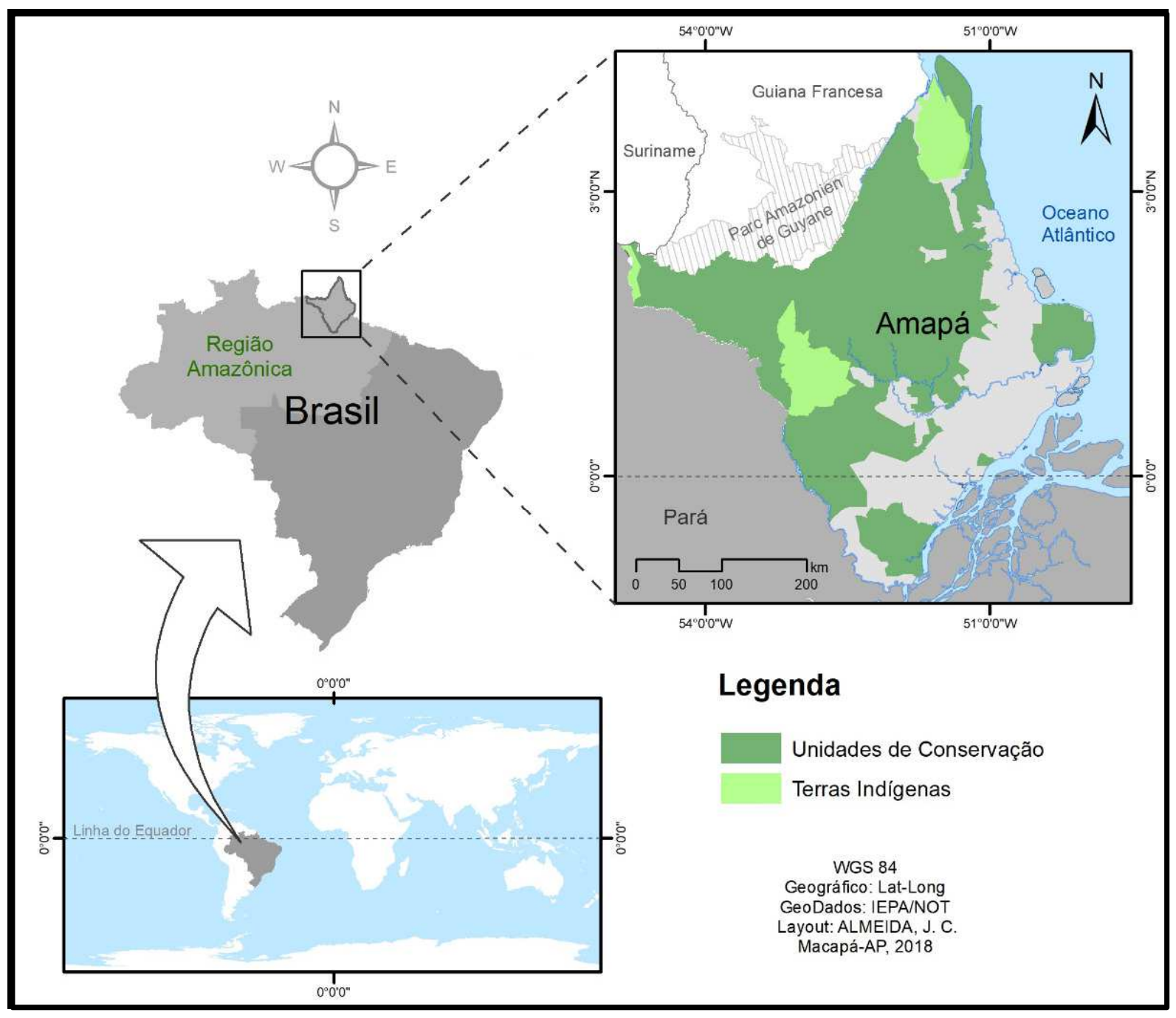

Figura 2 - Territórios singulares e áreas protegidas do Amapá, Amazônia Brasileira Fonte: Elaboração do geógrafo Jodson Cardoso Almeida. 


\section{Conexões entre o licenciamento ambiental e o desenvolvimento}

A PNMA dispõe de um conjunto de instrumentos que, por princípios da administração pública, aplicar-se-ão de forma integrada e planejada, de modo a assegurar condições ao desenvolvimento socioeconômico, aos interesses da segurança nacional e à proteção da dignidade da vida humana. O referido enunciado normativo camufla as tensões existentes dentro do Estado em relação a seus dois papéis: de protetor do meio ambiente e de promotor do desenvolvimento (DOMINGUES, 2007, p. 152).

As conexões entre política ambiental e desenvolvimento são instigantes, mas invisibilizadas pelo retardamento dos governos em fazer frente à modernidade dos negócios, que acabam por trilhar caminhos alternativos, voltados para uma política ambiental mais autônoma e globalizada, como no caso dos sistemas voluntários de gestão ambiental. Referidos sistemas certificam a política ambiental de atividades, serviços e produtos e, de certa forma, protegem os ativos ambientais das empresas diante do descrédito da gestão ambiental pública.

Entre os instrumentos da política ambiental, alguns ascenderam e se firmaram na condição de controle do poder público em resposta à degradação da qualidade ambiental, outros permaneceram ocultos, à espera de alguma lembrança orgânica e momentânea de cumprimento impositivo ou de revisão normativa que reconheça o que realmente importa diante de uma realidade cada vez mais próxima e hegemônica ao tempo dos negócios. A política ambiental, infelizmente, ainda mantém-se distante de discussões relativas a benefícios equânimes, justiça socioambiental e democracia participativa.

Como integrante da relação de instrumentos preventivos da PNMA, o licenciamento ambiental vincula a obrigação do poder público em gerenciar os impactos das atividades econômicas sobre a natureza e a sociedade. Constitui-se, desta forma, de procedimento administrativo pelo qual o poder público exerce papel fundamental, na tomada de decisão sobre a localização e instalação de atividades que possam causar degradação da qualidade ambiental e afetar a qualidade de vida de determinada população.

Em sua vertente de maior complexidade, o licenciamento ambiental articula-se com a avaliação de impacto para subsidiar a deliberação sobre a maneira em que se dará a implantação das atividades econômicas, ou sua própria negação diante do não atendimento 
dos requisitos normativos ou, mas raramente, pela constatação da inviabilidade socioambiental da atividade ou empreendimento.

Não se trata de um "jogo de quem ganha e quem perde", mas de um exercício onde os aspectos políticos são importantes, mas não determinantes para a tomada de decisão sobre a concessão do licenciamento ambiental pelo poder público, mesmo reconhecendo que o componente sedutor dos empregos gerados, do aumento da arrecadação tributária e da personificação da decisão pública sobre o licenciamento acabam exercendo forte influência no processo, como demonstrado por Serra (2018) em narrativa sobre o maior desastre ambiental do Brasil - "Tragédia em Mariana".

Nesse sentido, prevalece a crítica de que o licenciamento ambiental tornou-se "genérico" diante de prescrições para atividades onde a significância dos impactos não é materializada com base em critérios tecnicamente elaborados, ou em resposta ao que realmente deva ser objeto de controle do Estado, considerando a perspectiva de que o licenciamento possa contribuir para uma melhoria da qualidade de vida das gerações futuras (MILARÉ, 2016, p. 113).

A Resolução CONAMA 001/86 possibilita alguma reflexão em relação ao conceito de impacto ambiental. Estabelece em seu artigo 1ㅇq que "a saúde, a segurança e o bem-estar da população", entre outros aspectos, devem ser resguardados pelo poder público, diante dos impactos das atividades econômicas. Não desconsiderando a relevância de outros aspectos elencados na Resolução, quanto ao entendimento de impacto ambiental significativo, mas há mérito na priorização discricionária do que licenciar com base nos direitos fundamentais à vida, garantidos pela própria Constituição Federal.

Entende-se, dessa forma, que se faz necessário discernir as atividades quanto à significância dos impactos prioritariamente sobre as pessoas e, com isso, inverter a lógica predominante nos estudos ambientais que ancoram a decisão sobre o licenciamento ambiental, quanto à identificação de impactos sobre a natureza e pouco conectados às consequências sobre a qualidade de vida da população. Com isso, o licenciamento ambiental de atividades potencialmente causadoras de significativa degradação ambiental tornar-se-á mais humanista e passível de contribuir com o equacionamento de questões, que na maioria das vezes são negligenciadas ou rebatidas como bola de ping-pong quanto à responsabilização 
pelos impactos gerados, como no caso da saúde, da educação e da segurança da população afetada.

Atualmente, a definição de atividades de impactos significativos é realizada com base em listas positivas, listas negativas e estudos preliminares que adotam critérios relacionados ao porte, ao potencial poluidor e à localização da atividade (ABEMA, 2013). Ribeiro e Mota (2015) propõem a ampliação desses critérios, com a inclusão de potenciais benefícios em longo prazo, como por exemplo, a proteção da área para produção de água e a prestação de outros serviços ambientais. Critérios sociais relacionados a condições de vida da população têm sido secundarizados ou mesmo desconsiderados, o que fortalece o uso de avaliações ambientais preliminares participativas (base-line), de modo a aferir previamente os impactos a partir da visão da população a ser afetada pela atividade econômica.

Destaca-se que não se trata de desvio do instrumento da política ambiental, como é frequentemente comentado por operadores do licenciamento ambiental, mas sim de redirecioná-lo para adoção de critérios aferidos socialmente, no sentido de proporcionar maior segurança jurídica, transparência e antecipação de conflitos, o que permite ganhos de agilidade e eficácia quanto à contribuição ao desenvolvimento pautado na sustentabilidade.

De Estocolmo 72 a Rio+20, a questão ambiental vem se aproximando dos problemas sociais sob a égide do desenvolvimento sustentável. Percebe-se que as políticas ambientais em curso buscam cada vez mais contribuir para o desenvolvimento e com isso focar em desafios para além da visão preservacionista da natureza intocada. Esse parece o caso do profícuo diálogo entre os instrumentos da política ambiental e os objetivos de desenvolvimento sustentável da ONU ou Agenda 2030.

Reconhece-se, entretanto, que "desenvolvimento" é um tema de filiação dominantemente econômica, repleto de significados e ressignificados, assim como também são as percepções sobre natureza, meio ambiente e política ambiental. O problema é que a complexidade da equação "desenvolvimento/meio ambiente" tem, de forma reducionista, inserido a política ambiental e seu mais importante instrumento - o licenciamento ambiental - no "campo do denominador". 
As proposições de correção em rumo não passam pela simples revisão do instrumento, como bem observa a Associação Brasileira de Entidades Estaduais de Meio Ambiente (ABEMA):

\begin{abstract}
Neste contexto, a revisão e o aperfeiçoamento do licenciamento devem ser a partida para uma reforma mais ampla da PNMA, visando adicionar, além dos mecanismos de comando e controle, outras diretrizes com foco na sustentabilidade, o que exigirá esforço de atualização da Lei 6.938/81 e profundas mudanças nas políticas públicas setoriais, especialmente na política macroeconômica definidora das políticas tributária, fiscal e creditícia, desenhadas nos anos 1970, que, mesmo com alterações posteriores, deixou de contemplar a dimensão ambiental como indutora do desenvolvimento sustentável (ABEMA, 2014, p. 17).
\end{abstract}

A política ambiental tornou-se alvo do tempo imediatista dos negócios e com isso insurgemse proposições de flexibilização das regras vinculadas ao licenciamento, sob o argumento da complexidade dos procedimentos, da falta de celeridade e dos custos associados (BRASIL, 2018). A reforma mais ampla da PNMA, preconizada pela ABEMA, implica na reflexão inquietante sobre a condição política de sua própria existência e no descompasso com a agenda do desenvolvimento, sobretudo a considerar os ciclos de crise econômica e do poder político de plantão.

A este propósito e em profunda imersão normativa a procura de vínculos entre o licenciamento ambiental e o desenvolvimento, a Resolução CONMA 01/86, em seu artigo 50, inciso IV, inclui, entre as diretrizes gerais para a elaboração de Estudos de Impacto Ambiental (EIA), a consideração de planos e programas governamentais, propostos e em implantação na área de influência do projeto, e sua compatibilidade. A diretriz, em princípio, para ser atendida, prescinde da existência de algum instrumento de planejamento ou de ordenamento proposto para a região onde o projeto submetido ao licenciamento pretende se instalar.

Via de regra, o atendimento ao referido dispositivo é setorial e casuístico, ou seja, diante da existência de algum documento público que faça referência a planos e programas que tangenciem os interesses do projeto em questão, considera-se cumprido o requisito normativo, mesmo que sua compatibilidade não seja demonstrada ou que se reconheça a falta de integração do licenciamento com o planejamento voltado ao ordenamento territorial via zoneamento. 
Uma das razões apontadas por Egler (2001) para o distanciamento entre o planejamento e a avaliação de impacto deve-se à incompatibilidade dos processos de tomada de decisão que envolvem as alternativas e o empreendimento em questão, sendo a avaliação ambiental apenas considerada quando não existem mais alternativas a serem comparadas e avaliadas pelo empreendedor, ou seja, a avaliação ambiental passa a ser considerada uma decisão pontual, pós-fato consumado pelo empreendedor.

Na legislação brasileira, Milaré (2006) sinaliza que o licenciamento e a avaliação ambiental encontram-se consolidados como instrumentos indissociáveis da política ambiental e do planejamento, cabendo ao poder público o papel de prever antecipadamente os efeitos das políticas de desenvolvimento que se almeja como sustentável.

O licenciamento e a avaliação ambiental, nesse sentido, mesmo vinculados, se configuram pela evasiva competência de prever os impactos das atividades econômicas licenciadas pontualmente, consequência da ausência de procedimentos que induzam ao uso e ocupação territorial de forma justa e sustentável, como se propõe o zoneamento.

\section{Licenciamento Ambiental e Zoneamento Ecológico-Econômico}

Um dos problemas enfrentados pelo Estado é conduzir o licenciamento ambiental integrado ao Zoneamento Ecológico-Econômico (ZEE). Com relação à Amazônia brasileira, desde 1995

o ZEE é pauta propositiva do Governo Federal para o ordenamento territorial da região (Quadro 1). 


\begin{tabular}{|c|c|}
\hline Documento & Síntese executiva e o Amapá \\
\hline $\begin{array}{c}\text { Política Nacional Integrada } \\
\text { para a Amazônia Legal (1995) }\end{array}$ & $\begin{array}{l}\text { Elaborado no Governo Fernando Henrique Cardoso. Traz uma vertente } \\
\text { desenvolvimentista assente em "superar um ecologismo estritamente } \\
\text { preservacionista, para assumir um ecologismo voltado para o } \\
\text { desenvolvimento". Propõe três diretrizes gerais: I - Reorientação do } \\
\text { Crescimento Econômico; II - Integração Interna e Externa; III - } \\
\text { Valorização Humana. }\end{array}$ \\
\hline $\begin{array}{l}\text { Plano Amazônia Sustentável } \\
\qquad(2006)\end{array}$ & $\begin{array}{l}\text { Elaborado no Governo Lula. O Plano propõe cenários para o } \\
\text { desenvolvimento regional com base em três recortes territoriais: 1) Arco } \\
\text { do Povoamento Adensado; } 2 \text { ) Amazônia Central e; 3) Amazônia } \\
\text { Ocidental. O Amapá encontra-se inserido em quase sua totalidade na } \\
\text { macrorregião da Amazônia Central (microrregião Fronteira de } \\
\text { Preservação). }\end{array}$ \\
\hline $\begin{array}{l}\text { Um projeto para a Amazônia } \\
\text { no século 21: desafios e } \\
\text { contribuições (2009) }\end{array}$ & $\begin{array}{l}\text { Documento que articula o urbano e a floresta, com projeções de uma } \\
\text { região pensada com e sem mata. Descreve processos e dinâmicas em } \\
\text { curso que projetam a Amazônia sem mata, mas com proposições de } \\
\text { intervenções favoráveis à reversão pela regularização fundiária, } \\
\text { zoneamento ecológico-econômico e organização produtiva. }\end{array}$ \\
\hline
\end{tabular}

Quadro 1 - Políticas de governo para a Amazônia com inserção do ZEE

Fonte: Brasil (1995; 2006; 2009).

Na Política Nacional Integrada para a Amazônia Legal constam os primeiros exercícios de zoneamento para a região, com projeção de três zonas: 1) Produtivas; 2) Críticas e; 3) Especiais. No Plano Amazônia Sustentável (PAS), o ordenamento territorial está entre as principais diretrizes para a promoção da regularização fundiária, proteção dos ecossistemas e dos direitos das populações tradicionais, bem como para melhor destinação das terras para a exploração produtiva. Por último, no documento "Um projeto para a Amazônia no século 21", a regularização fundiária e a implementação do zoneamento ecológicoeconômico são apresentadas como os principais desafios da região.

No caso específico do estado do Amapá, enquanto o licenciamento se vinculou à estrutura do órgão ambiental, o ZEE seguiu uma trajetória independente, mais próxima da pesquisa, a considerar os procedimentos metodológicos propostos por Bertha e Egler (1996) e a 
ausência de base de dados espaciais sobre o Estado que possibilitasse a produção das cartas temáticas e da carta-síntese de subsídio à gestão do território.

O marco do licenciamento ambiental e do ZEE no Amapá, assim como na maioria dos estados da Amazônia, está associado ao apoio de programas de cooperação internacional voltados para o controle do desmatamento da Floresta Amazônica, com destaque para o Programa Piloto para a Proteção das Florestas Tropicais do Brasil (PPG-7). No âmbito deste Programa, o Subprograma de Política de Recursos Naturais (SPRN) responde pelos primeiros passos da gestão ambiental no Amapá e da maioria dos estados da Região Amazônica.

A partir de 1995, o SPRN apoiou um conjunto de ações voltadas para o fortalecimento dos instrumentos da política ambiental, com ênfase no licenciamento ambiental e no ZEE. Com relação ao primeiro, os resultados foram mais normativos do que operacionais. De fato, se consolidou nos estados da Amazônia Brasileira toda uma legislação ambiental aplicada ao comando e controle, mas os recursos investidos pelo SPRN não possibilitaram estruturar um sistema eficaz e eficiente de licenciamento, monitoramento e fiscalização.

Chagas (2003, p. 99-100) justifica referida constatação pelas dificuldades inerentes ao processo de descentralização das competências federal para estadual e pela ausência de componente de sustentabilidade financeira, que pudesse manter os custos de modernização tecnológica para comando e controle nos estados. Por outro lado, os estados se beneficiaram dos recursos da cooperação sem demonstrar compromissos de longo prazo com a gestão ambiental.

Quanto ao ZEE, por mais que a Amazônia apresente um "biozoneamento" representado pelas áreas protegidas, o instrumento não se tornou apenas um "mapa verde" na complexa teia de relações ecológicas e sociais da região. No caso do Amapá, por exemplo, um estado que contribui com $70 \%$ de seu território para a conservação da biodiversidade, o histórico do ZEE acumula inovações/adaptações conceituais e metodológicas com imensurável contributo ao planejamento e à gestão socioambiental do território, mas de pouca apropriação política.

A falta de sustentabilidade ou transversalidade política do ZEE, apontada por Souza (2008), também se observa quanto ao reposicionamento técnico do instrumento junto às etapas dos processos de licenciamento ambiental de significativo impacto ambiental, o que 
certifica a falta ou dificuldade de integração entre os instrumentos da política ambiental pelos estados.

Com produtos elaborados em escala estadual, municipal e para o bioma do cerrado amapaense (AMAPÁ, 2000; 2002; 2004; 2005; 2016), o ZEE do Amapá consolidou uma base multidimensional de informações dinâmicas que, para além de qualquer sistematização formal normativa, poderia ser mais bem aproveitada; acionada, por exemplo, como uma espécie de "ouvidoria" ao licenciamento ambiental de maior complexidade, mediando o diálogo entre o ambiental e o socioeconômico diante das análises e dos procedimentos ainda pouco transparentes e democráticos dos órgãos ambientais.

Em sua vertente estratégica, Sousa (2008, p. 355) faz lembrar que o ZEE "se constitui em um instrumento que subsidia o planejamento para o desenvolvimento sustentável e um catalisador para integração das políticas em um território". Cabe, então, instigar a inserção metodológica da avaliação ambiental no processo de re(afirmação) política do ZEE. Referida proposição pode se dar pela adoção da Avaliação Ambiental Estratégica (AAE), que em muitos aspectos se confunde com o próprio ZEE quanto à orientação do uso e da ocupação de um dado território ou de um setor econômico (THEODORO; BARROS, 2011, p. 27).

\section{Licenciamento Ambiental e Avaliação Ambiental Estratégica}

Atualmente, no Brasil, não existem vínculos entre o licenciamento ambiental e a AAE pela ausência de regulamentação deste instrumento de planejamento, no âmbito da administração pública, e pelo desconhecimento operacional. Enquanto a maioria dos países já adota a AAE para aferir preventivamente os efeitos de suas políticas públicas de desenvolvimento, no Brasil a AAE ainda é utilizada precariamente, não apresentando alinhamento com políticas, planos e programas governamentais.

Experiências de inserção da $A A E$ no âmbito do governo federal se deram por iniciativa do Ministério do Meio Ambiente (MMA) nos idos dos anos 2000, com consultoria de Maria Rosário Partidário, uma das referências mundiais em $A A E^{1}$. Na época, os encaminhamentos

\footnotetext{
${ }^{1}$ Homepage de Maria do Rosário Partidário: http://www.civil.ist.utl.pt/ mrp/.
} 
se efetivaram no sentido de inserir a AAE no âmbito do Plano Plurianual (PPA), com ênfase para agrupamentos de projetos identificados para o desenvolvimento sustentável da Amazônia, o que não se concretizou (BRASIL, 2002, p. 74).

A AAE, assim como o ZEE, não faz parte do ciclo de planejamento de políticas públicas no Brasil, sendo seus usos casuísticos, ou meramente lembrando diante de interesses que se findam nas competências setoriais de governo, como no caso dos inventários de bacias hidrográficas, apesar de se reconhecer alguma incorporação gradativa pelos planos e programas do setor de logística, transporte e turismo, com estímulos de agências multilaterais de desenvolvimento (PELLIN et al., 2011).

No caso do setor hidrelétrico, os inventários de aproveitamentos situados em bacias hidrográficas têm adotado a Avaliação Ambiental Integrada (AAI) de forma similar a AAE, considerando os efeitos cumulativos e sinérgicos dos impactos sobre os recursos naturais e as populações humanas de potenciais barramentos.

A AAE e a AAI não apresentam aparente distinções conceituais. Ambas estão na interface da avaliação ambiental aplicadas ao planejamento estratégico, se distinguindo apenas pelo fato da AAl ser utilizada pelo setor hidrelétrico quando da realização de inventários de possíveis barramentos em bacias hidrográficas, o que induz a proposições de ajustes para se aferir procedimentos metodológicos consistentes de avaliação ambiental.

A $A A E$, entretanto, é bem diferenciada enquanto sua aplicação em relação a AIA. Enquanto este é utilizado pelo setor elétrico para o conhecimento prévio dos impactos de projetos específicos (inventários de bacias hidrográficas), a AAE se insere no foco do planejamento estratégico nos níveis da política, de planos e de programas, antes que projetos econômicos se insiram em contextos conflituosos, mesmo diante de janelas de oportunidades de mercado. A figura 3, adaptada de $\operatorname{OECD}(2012$, p. 30) dá uma dimensão dos instrumentos de avaliação ambiental e de seus níveis de aplicação. 


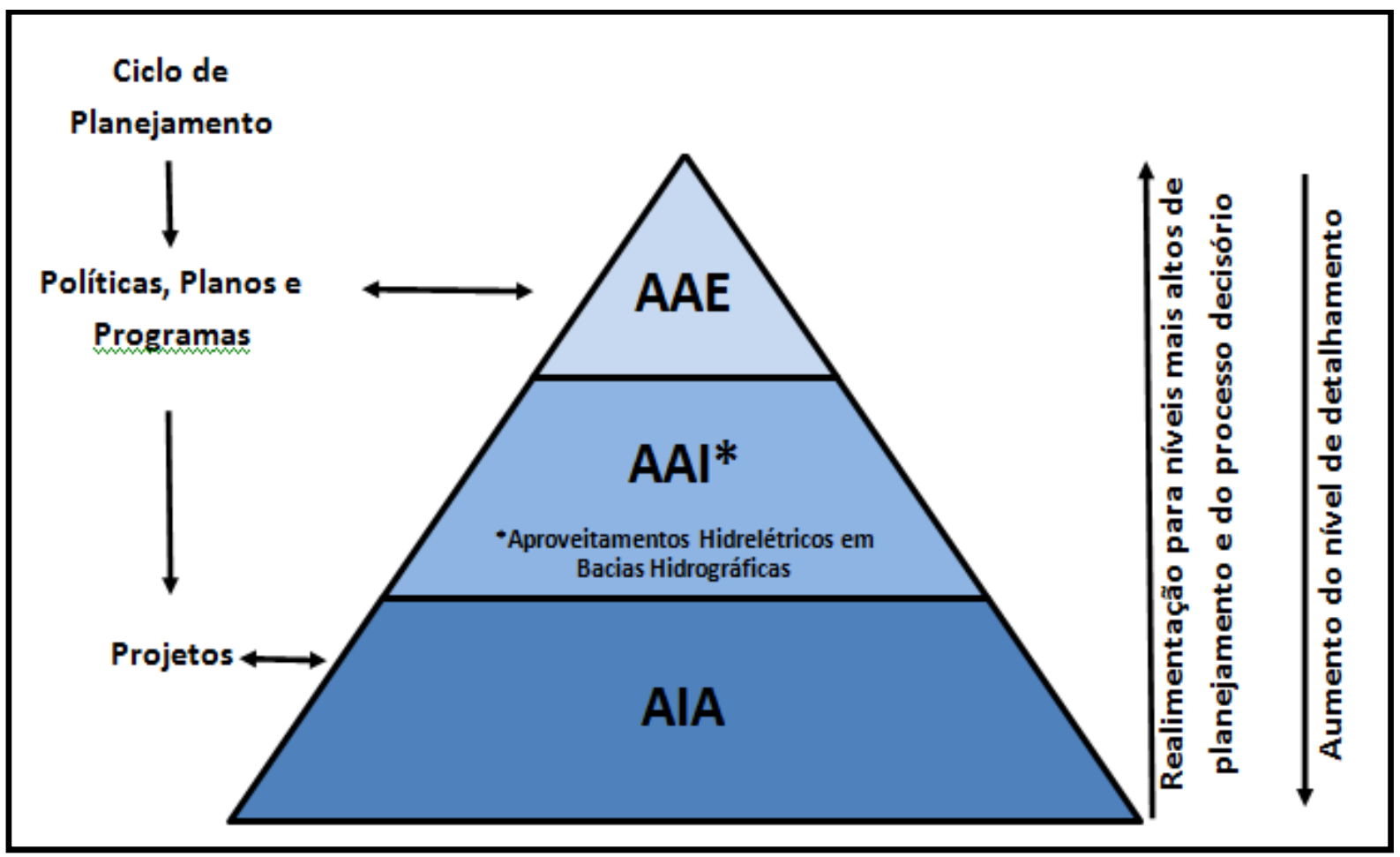

Figura 3 - Aplicação da AAE, AAI e AIA

Fonte: Elaboração dos autores com base em OECD (2012).

O licenciamento ambiental apresenta interface direta com a AIA e com o ZEE, enquanto que a $A A E$ ou mesmo a AAI ainda se ressente de melhor aparelhamento para potencializar os benefícios de políticas, planos e programas, principalmente quanto à tomada de decisão sobre o desenvolvimento a ser seguido.

\section{Licenciamento Ambiental de Alta Complexidade no Amapá}

Em 1994, o Estado do Amapá formulou sua política ambiental com a promulgação do Código de Proteção ao Meio Ambiente (Lei Complementar no 005/94). Nesse mesmo período, o licenciamento ambiental passou a receber aporte financeiro do PPG7 com objetivo de fortalecimento da política ambiental estadual para controle do desmatamento da floresta amazônica.

Ao avaliar os resultados dos investimentos do PPG7 no Amapá, Chagas (2003, p. 99) comenta que houve avanços no fortalecimento dos instrumentos de comando e controle, 
mas que a ausência de uma sistemática para a gestão compartilhada e descentralizada dos processos de licenciamento entre a União e o Estado imprimiu um caráter meramente formal de repasse de competências, para o qual o Estado não estava preparado.

Até 1989, os processos de licenciamento ambiental no Amapá eram conduzidos pela extinta Secretaria Especial de Meio Ambiente da Presidência da República (SEMA/PR - 1973-1989) e a partir desse ano passou à competência do então recém criado IBAMA, que, segundo Chagas (2013, p. 109), manifestou-se de imediato pelo repasse para o Estado sob a alegação de dificuldades para o exercício da fiscalização e do monitoramento dos empreendimentos licenciados no Amapá (Quadro 2):

\begin{tabular}{|c|l|l|l|}
\hline No & \multicolumn{1}{|c|}{ Processo } & \multicolumn{1}{|c|}{ Empreendimento/Atividade } & \multicolumn{1}{|c|}{ Finalidade } \\
\hline 1 & Proc. $868 / 84$ & Companhia de Dendê do Amapá - CODEPA & Plantio e beneficiamento de dendê \\
\hline 2 & Proc. $2.020 / 84$ & Companhia Caulim da Amazônia - CADAM & Mineração de caulim \\
\hline 3 & Proc. $572 / 87$ & Usina Hidrelétrica de Santo Antônio do Jari - JARI & Produção de energia \\
\hline 4 & Proc. $1.204 / 87$ & Indústria e Comércio de Minérios - ICOMI & Mineração de manganês \\
\hline 5 & Proc. $2.125 / 87$ & Companhia Ferro-ligas do Amapá - CFA & Siderurgia de ligas metálicas \\
\hline 6 & Proc. $712 / 88$ & Mineração Novo Astro - MNA & Mineração de ouro \\
\hline 7 & Proc. $2.076 / 88$ & Mineração Yukio Yoshidome - MYYSA & Mineração de ouro \\
\hline 8 & Proc. $2.475 / 88$ & Lab. Químico da MNA & Análises laboratoriais \\
\hline
\end{tabular}

Quadro 2 - Processos de licenciamento ambiental conduzido pela SEMA/IBAMA no Amapá até 1989 Fonte: Modificado de Chagas (2013).

Dos oito (8) processos de licenciamento ambiental em curso no IBAMA até 1989, quatro (4) eram de mineração, setor que exige requisitos de qualificação técnica e recursos tecnológicos para o exercício do comando e controle ambiental. O processo de licenciamento ambiental da Mineração Novo Astro foi a primeira experiência de descentralização do IBAMA para o Estado do Amapá (CHAGAS, 2013, p. 109-110).

Segundo dados de 2018, existem 23 processos de licenciamento ambiental em tramitação no IBAMA, ancorados em diferentes tipologias de AIAs, com predomínio de EIAs (Quadro 3). 


\begin{tabular}{|c|c|c|c|c|}
\hline № & Processo & Empreendimento/Licença Ambiental & AIA & Obs \\
\hline 1 & 02001.000337/2008-06 & $\begin{array}{l}\text { UHE Santo Antônio (Rio Jari)/LO 1233/2014 - 1ạ } \\
\text { Retificação em 09/03/2015 }\end{array}$ & EIA & $\begin{array}{l}\text { Um primeiro EIA foi } \\
\text { elaborado em } 1987 \\
\text { (Processo 572/87) }\end{array}$ \\
\hline 2 & 02001.004576/2013-94 & Cassitan - Santo Antônio & --- & Sem Informação \\
\hline 3 & $02001.004575 / 2013-40$ & Cassitan - Santo Antônio Norte & --- & Sem Informação \\
\hline 4 & 02004.000529/2000-27 & $\begin{array}{l}\text { Exploração Seixo e Areia no Rio Oiapoque/LO } \\
1376 / 2017\end{array}$ & PCA & Processo iniciado em 2000 \\
\hline 5 & 02001.004484/2013-12 & Mineração Cassitam Ltda - Me & --- & Sem informação \\
\hline 6 & 02001.004574/2013-03 & SAH - Gavião Leste & --- & Sem informação \\
\hline 7 & 02001.001266/2000-01 & $\begin{array}{l}\text { BR } 156 \text { - Trecho entre a Ponte Tracajatuba - } \\
\text { Oiapoque/LI 929/2013 - Solicitação Renovação } \\
\text { em 29/08/2016 }\end{array}$ & EIA & Processo iniciado 2000 \\
\hline 8 & 02001.006188/2001-12 & $\begin{array}{l}\text { BR } 156 \text { AP - Trecho: Rio Tracajatuba - Igarapé do } \\
\text { Breu (km 353-471)/LI 141/2002 }\end{array}$ & EIA & $\begin{array}{l}\text { Processo iniciado } 2001 \text { e } \\
\text { sem movimentação }\end{array}$ \\
\hline 9 & 02001.004452/2004-18 & $\begin{array}{lllll}\text { BR } 156 \text { AP }- \text { Trecho Laranjal do Jari } & - \\
\text { Entroncamento BR 210/AP/LI 1174/2017 } & & \end{array}$ & EIA & Processo iniciado 2004 \\
\hline 10 & 02001.006629/2004-11 & $\begin{array}{l}\text { BR } 156 \text { e BR } 210 \text { - Trecho Macapá - Tracajatuba } \\
\text { LO 880/2009 - Solicitação de LI em 07/12/2015 }\end{array}$ & --- & Processo iniciado 2004 \\
\hline 11 & 02001.006810/2006-99 & BR 210 AP - Rio Paru D'Este - Rio Marapi & --- & Sem informação \\
\hline 12 & 02001.003221/2003-14 & $\begin{array}{l}\text { Ponte Binacional Rio Oiapoque - BR 156/LO } \\
1373 / 2017\end{array}$ & EIA & LO 1373/2017 \\
\hline 13 & 02001.004437/2013-61 & $\begin{array}{l}\text { Regularização Obra Fibra Óptica Estado do } \\
\text { Amapá }\end{array}$ & EIA & $\begin{array}{l}\text { (Delegado a SEMA/AP pelo } \\
\text { ACT 02/2014) - Sem } \\
\text { informação }\end{array}$ \\
\hline 14 & 02001.006411/2010-12 & $\begin{array}{l}\text { Sistema de Abastecimento de Água } \\
\text { Comunidade de Vila Betel/Solicitação LP em } \\
03 / 09 / 2010\end{array}$ & --- & Sem movimentação \\
\hline 15 & 02001.005079/2006-84 & $\begin{array}{l}\text { Antena ERB - FLONA Saracá-Taquera/LP } \\
\text { 249/2007 - Solicitação LO em 17/03/2009 }\end{array}$ & --- & Sem movimentação \\
\hline 16 & 02001.000534/2014-65 & PCH Salto Cafesoca/LP 566/2018 & RAS & LP 566/2018 \\
\hline 17 & 02001.001118/2002-41 & $\begin{array}{l}\text { Mineroduto Vitória do Jari }- \text { Almerim/LO } \\
313 / 2003-2 \text { a Renovação em 22/12/2015 }\end{array}$ & --- & $\begin{array}{l}\text { Lapsos temporais de } \\
\text { renovação }\end{array}$ \\
\hline 18 & 02001.000912/2015-91 & $\begin{array}{l}\text { Linhas de Laranjal Transmissora de Energia/LP } \\
534 / 2016\end{array}$ & RAS & --- \\
\hline 19 & $02001.004314 / 2008-62$ & $\begin{array}{l}\text { LT Jurupari - Oriximiná e Jurupari-Laranjal do } \\
\text { Jari-Macapá (Lote B Linhão de Tucurui)/LO } \\
1218 / 2014 \text { - Solicitação de Renovação em } \\
07 / 02 / 2018\end{array}$ & EIA & --- \\
\hline 20 & 02001.000639/2013-33 & $\begin{array}{l}\text { Sistema de Distribuição de Energia Elétrica } 69 \text { KV } \\
\text { Laranjal do Jari/Monte Dourado/LI 1127/2016 }\end{array}$ & RAS & --- \\
\hline 21 & $02022.000327 / 2014-6$ & $\begin{array}{l}\text { Perfuração Marítima nos blocos FZA-M-57, 86, } \\
88,125 \text { e 127, na Bacia da Foz do Amazonas }\end{array}$ & EIA & $\begin{array}{l}\text { Em análise - Audiências } \\
\text { públicas realizadas }\end{array}$ \\
\hline 22 & 02022.000336/2014-53 & $\begin{array}{l}\text { Perfuração Marítima nos blocos FZA-M-59, na } \\
\text { Bacia da Foz do Amazonas }\end{array}$ & EIA & $\begin{array}{l}\text { Em análise - Audiências } \\
\text { públicas realizadas }\end{array}$ \\
\hline 23 & 02022.000390/2014-07 & $\begin{array}{l}\text { Perfuração Marítima nos blocos FZA-M-90, na } \\
\text { Bacia da Foz do Amazonas }\end{array}$ & EIA & Em análise \\
\hline
\end{tabular}

Quadro 3 - Processos de licenciamento ambiental no Amapá

Fonte: IBAMA - Sistema Informatizado de Licenciamento Ambiental Federal.

Dos vinte e três (23) processos de licenciamento ambiental conduzidos pelo IBAMA, prevalecem as atividades de infraestrutura rodoviária e de energia (11), seguidos de 
mineração (09) e outros de menor importância quanto à significância dos impactos (03) (Figura 4).

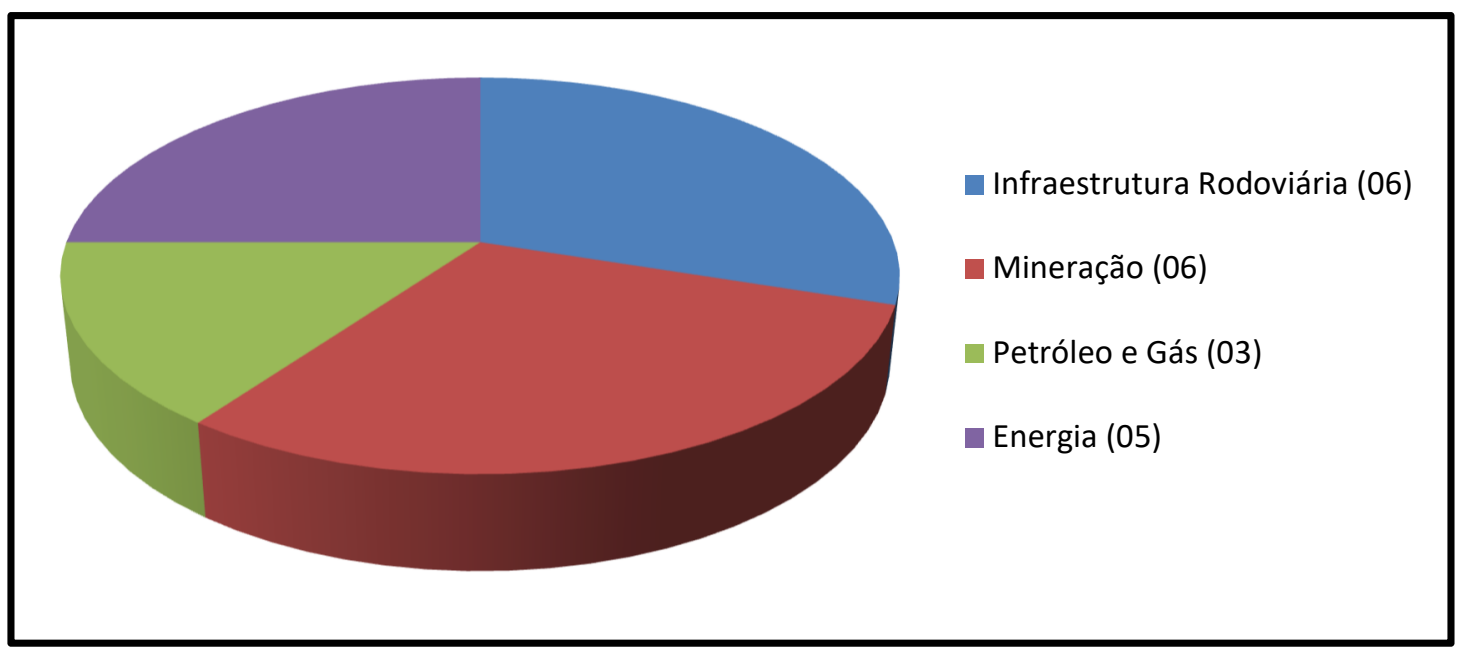

Figura 4 - Processos de licenciamento ambiental federal no Amapá por atividade Fonte: Elaboração dos autores com base no IBAMA - Sistema Informatizado de Licenciamento Ambiental Federal.

Com relação à atividade de infraestrutura rodoviária, chama atenção o licenciamento ambiental da pavimentação da BR-156, que se prolonga por mais de 20 anos, com diferentes iniciativas de protocolos sobre o mesmo objeto, inferindo percepções de descontinuidades e ausência de planejamento governamental.

No setor de infraestrutura de energia, o licenciamento ambiental da Usina Hidrelétrica Santo Antônio, no Rio Jari, exerce maior atenção quanto aos procedimentos de controle e monitoramento pós-licenciamento, seguido das obras vinculadas a linhas de transmissão.

No setor de mineração, três (03) processos de licenciamento ambiental de atividades de petróleo e gás na costa marítima do Amapá inferem atenção pelo seu caráter diferenciado de gestão dentro da estrutura do IBAMA e pela significância dos impactos. Esses processos encontram-se com pendências e incertezas para a emissão da licença ambiental (IBAMA, 2018). Os demais licenciamentos do setor de mineração não apresentam informação na base de dados e encontram-se sem movimentação.

No âmbito estadual, não existe uma base de dados informatizada sobre o licenciamento ambiental, o que demonstra o atraso da política ambiental e dos procedimentos de transparência pública do Estado. Segundo registros de 2018, obtidos em pesquisa no acervo 
do órgão estadual de meio ambiente, existem doze (12) processos de licenciamento submetidos à EIA (Quadro 4).

\begin{tabular}{|c|c|c|}
\hline № & Empreendimento & Ano/Responsável \\
\hline 1 & Mineração de Tantalita & Processo de 2002 - Minerais e Metais Comércio e Indústria \\
\hline 2 & Revitalização do Setor Comercial -Portuário de Santana & Processo de 2003 - Prefeitura Municipal de Santana \\
\hline 3 & Silvicultura & Processo de 2004 - AMCEL \\
\hline 4 & Ampliação do Aeroporto Internacional de Macapá & Processo de 2006 - Governo do Amapá \\
\hline 5 & Terminal de Minérios e Metálicos do Amapá & Processo de 2006 - Mineração MMX \\
\hline 6 & Projeto Amapari - Expansão Minério de Ferro da MPBA & Processo de 2006 - Mineração MMX \\
\hline 7 & PCH Capivara & Processo de 2008 - Amapari Energia \\
\hline 8 & Projeto Tracajatuba & Processo de 2010 - Zamapá Mineração \\
\hline 9 & UHE Ferreira Gomes & Processo de 2010 - Odebrecht - transferido para Alupar \\
\hline 10 & UHE Cachoeira Caldeirão & Processo de 2011 - Odebrecht - transferido para EDP \\
\hline 11 & $\begin{array}{l}\text { Terminal Portuário de Uso Privativo - TPUP e Unidade } \\
\text { Industrial para Armazenamento e Beneficiamento de Grãos - } \\
\text { Ilha de Santana }\end{array}$ & Processo de 2012 - Cianport \\
\hline 12 & $\begin{array}{l}\text { Regularização Obra Fibra Óptica Estado do Amapá (Delegado } \\
\text { pelo IBAMA a SEMA/AP pelo ACT 02/2014) }\end{array}$ & Processo de 2013 -Telemar \\
\hline
\end{tabular}

Quadro 4 - Processos de licenciamento ambiental submetidos à EIA obtidos em pesquisa no acervo do órgão estadual de meio ambiente do Amapá

Fonte: Acervo do órgão estadual de meio ambiente do Amapá (2018).

A análise comparativa dos processos permite aferir o caráter embrionário de modernização do licenciamento ambiental no Amapá. Enquanto o IBAMA disponibiliza os processos online, o órgão ambiental do estado do Amapá ainda mantém tudo em condição material, o que invariavelmente implica em pouca transparência, morosidade e excesso de burocracia.

A Lei Complementar 140/2011, que se propôs a clarear as competências da União, dos Estados e Municípios em matéria ambiental, não resolveu questões políticas em relação à implementação de boas práticas de licenciamento ambiental. No caso do Amapá, a considerar os problemas de transparência do licenciamento ambiental, faz-se necessária profícua cooperação União-Estado para que o instrumento supere o dilema de entrave ou de decisão meramente política. 
De fato, casos citados por Chagas (2013) em que o licenciamento ambiental conduzido pelo Estado adentrou ao campo das abordagens de negociações políticas não vinculadas aos impactos, principalmente aqueles relacionados a interesses políticos partidários, colocam o IBAMA ou mesmo o Ministério Público em constante alerta quanto à autonomia da política ambiental do Estado.

Quando particularizado, o instrumento do licenciamento ambiental prescinde de modernização tecnológica uniforme entre os entes federados. A iniciativa do Portal Nacional de Licenciamento Ambiental (PNLA), ferramenta disponibilizada pelo MMA, pouco impulsionou o cumprimento da Lei $10.650 / 2003$, que dispõe sobre o acesso público aos dados e informações existentes nos órgãos e entidades integrantes do Sistema Nacional de Meio Ambiente (SISNAMA).

Além de maior transparência, o fortalecimento dos vínculos entre o licenciamento ambiental e outros instrumentos da política ambiental, sobretudo o ZEE e a AAE, é defendido por Agra Filho (2014, p. 156), Ribeiro (2015, p. 25) e Sánchez (2017, p. 174). Em estados com tantas singularidades ambientais e sociais, como o Amapá, e a considerar que o número de licenciamentos ambientais de maior complexidade, submetidos à EIA, pode-se "contar nos dedos da mão", o ZEE e a AAE deveriam receber maior atenção política enquanto alternativa de planejamento e de mediação de potenciais conflitos.

\section{Conclusão}

O licenciamento ambiental é um dos mais importantes instrumentos de política ambiental do Brasil, mas se ressente de um esforço de renovação e de integração, sob o risco de sua desconstrução e flexibilização normativa. A renovação passa pela sua modernização tecnológica e celeridade, como se observa pelos esforços do MMA e do IBAMA em disponibilizar os processos em plataforma on-line para consulta pública e em cumprir prazos legais. Outras variáveis também apresentam implicações nesse processo, como a existência de recursos humanos qualificados e a autonomia técnica. 
O licenciamento ambiental de alta complexidade, suscetível à apresentação de EIA, traz em seu bojo a necessidade de aferir entendimentos prévios com a população a ser afetada sobre o conceito de impacto ambiental, com objetivo de priorizar o que realmente importa no licenciamento quando da identificação e avaliação dos impactos socioambientais de determinada atividade econômica, mesmo reconhecendo que esse caminho não segue a trajetória, tecnocrática, pouco democrática, dos procedimentos e normas que regulam o instrumento.

No caso do Amapá, estado amazônico dos mais sociobiodiversos, que apresenta $70 \%$ de seu território transformado em áreas protegidas, incluindo unidades de conservação e terras indígenas, a situação do licenciamento ambiental é mais complexa e com forte potencial para conflitos cíclicos infindáveis, em que pese o baixo número de processos de licenciamento ambiental em curso.

Verifica-se ainda que a maioria dos processos se arrastam por longos anos, alguns com ausência de movimentação protocolar, estes quase sempre relacionados a alguma obra pública que parece avançar, à medida da liberação de recursos federais por emendas parlamentares, demonstrando a ausência de planejamento estratégico. As obras públicas iniciam, mas não se tem a mínima ideia de quando será finalizada, com repercussão negativa ao controle ambiental.

Também se observa no Amapá a existência de licenciamentos de atividades destinadas à exploração de recursos naturais que apresentam rigidez locacional (mineração, construção de hidrelétricas, exploração de petróleo, etc.). Esses são mais céleres e com melhor acompanhamento sistemático dos órgãos ambientais de controle ambiental, em que pese escassas informações pós-licenciamento ambiental, quando de fato afloram conflitos decorrentes de impactos socioambientais negligenciados.

Uma das alternativas para a melhoria do sistema de licenciamento ambiental, entendido como potencial contribuinte ao desenvolvimento, passa pela re(valorização) do ZEE e pela aplicação e integração com a $\mathrm{AAE}$, de modo a instruir o processo de planejamento público quanto à identificação de vulnerabilidades socioambientais regionais e da sempre delicada delimitação das áreas de influência dos impactos de determinadas atividades econômicas. 
Referido caminho é longo, pela frágil componente política do ZEE e pelos tímidos avanços da AAE no País. Mas, a considerar estados com poucos processos de licenciamento de alta complexidade, como no caso do Amapá, e ainda as especificidades socioambientais que constituem o território e suas territorialidades, investimentos no ZEE e em AAE inferem a possibilidade de superação do dilema desenvolvimento e preservação pelo planejamento estratégico.

A contribuição da política ambiental ao desenvolvimento também requer alguma radicalidade democrática. Sabe-se o quanto os instrumentos da política ambiental são tecnocráticos e descontextualizados das realidades onde operam. Isso tem reduzido a política ambiental à condição de entrave ao desenvolvimento ou ainda de intermináveis processos judiciais.

Os instrumentos da política ambiental têm sido mais reativos do que proativos e dessa forma submergido à condição subalterna dos ciclos econômicos. No caso do licenciamento ambiental, que se encontra sob ameaça de flexibilização e descredenciamento no Brasil, a sua sobrevida pública parece estar associada à busca de maior integração com outros instrumentos e de maior inserção aos mecanismos de controle social para, assim, se aferir alguma hipótese de sua contribuição ao desenvolvimento, mesmo reconhecendo que esse conceito é polissêmico e multidimensional.

\section{Referências bibliográficas}

ASSOCIAÇÃO BRASILEIRA DE ENTIDADES ESTADUAIS DE MEIO AMBIENTE - ABEMA. Novas propostas para o licenciamento ambiental no Brasil. Organização José Carlos Carvalho. Brasília: ABEMA, 2013.

AGRA FILHO, S. S. Planejamento e Gestão Ambiental no Brasil: os Instrumentos da Política de Meio Ambiente. Rio de Janeiro: Elsevier, 2014. ISBN 978-85-3528-008-1.

AMAPÁ. Instituto de Pesquisas Científicas e Tecnológicas do Estado do Amapá. Atlas do Zoneamento Ecológico-Econômico da Área Sul do Estado do Amapá. Macapá: IEPA, 2000.

AMAPÁ. Instituto de Pesquisas Científicas e Tecnológicas do Estado do Amapá. Laranjal do Jari: Realidades que devem ser conhecidas. Macapá: IEPA, 2004. [Consultado 03 Novembro 2018]. Disponível em: http://www.iepa.ap.gov.br/biblioteca/publicacoes/laranjal-do-jari-web.pdf.

AMAPÁ. Instituto de Pesquisas Científicas e Tecnológicas do Estado do Amapá. Macrodiagnóstico do Estado do Amapá: Primeira Aproximação do ZEE. Macapá: IEPA, 2002. 
AMAPÁ. Instituto de Pesquisas Científicas e Tecnológicas do Estado do Amapá. Mazagão: Realidades que devem ser conhecidas. Macapá: IEPA, 2005. [Consultado 29 Setembro 2018]. Disponível em: http://www.iepa.ap.gov.br/not/publicacaoes/mazagao final.pdf.

AMAPÁ. Instituto de Pesquisas Científicas e Tecnológicas do Estado do Amapá. Zoneamento Socioambiental do Cerrado do Estado do Amapá. Macapá: IEPA: EMBRAPA, 2016. [Consultado 29 Setembro 2018]. Disponível em: http://www.iepa.ap.gov.br/biblioteca/publicacoes/relatorio cerrado 2016 17.pdf.

ARRUDA JUNIOR, P.; ANDRADE, R. C. Licenciamento Ambiental: Aspectos Gerais sobre o Instituto e a (In)Eficaz Lei Complementar 140/2011. In RIBEIRO, J. C. J. Licenciamento Ambiental: Herói, Vilão ou Vítima. Belo Horizonte: Arraes Editores, 2015. p. 110-128. ISBN 978-85-823-8153-3.

BECKER, B. K.; EGLER, C. A. G. Detalhamento da metodologia para execução do zoneamento ecológicoeconômico pelos estados da Amazônia Legal. Rio de Janeiro: Convênio SAE/MMA/LAGET/UFRJ, 1996.

BRASIL. Ministério do Meio Ambiente. Política Nacional Integrada para a Amazônia Legal. Brasília, 1995.

BRASIL. Ministério do Meio Ambiente. Avaliação Ambiental Estratégica. Brasília: MMA/SQA, 2002.

BRASIL. Ministério do Meio Ambiente. Programa Amazônia Sustentável. Resumo Executivo. Brasília, 2006.

BRASIL. Ministério de Ciência e Tecnologia. Centro de Gestão e Estudos Estratégicos. Um projeto para a Amazônia no século 21: desafios e contribuições. Brasília, 2009.

BRASIL. Senado Federal. Projeto de Lei do Senado № 168/2018. Regulamenta o licenciamento ambiental previsto no inciso IV do $\S 1$ 으 do art. 225 da Constituição Federal e dispõe sobre a avaliação ambiental estratégica. Brasília: Senado Federal, 2018. [Consultado 07 Janeiro 2019]. Disponível em: https://www25.senado.leg.br/web/atividade/materias/-/materia/132865.

CHAGAS, M. A. Gestão Ambiental no Amapá: Evolução e Contribuição do Subprograma de Política de Recursos Naturais do PPG7. Dissertação (Mestrado em Desenvolvimento Sustentável) - Centro de Desenvolvimento Sustentável. Universidade de Brasília, Brasília, 2003. ISBN 978-85-7617-255-0.

DOMINGUES, J. M.; PONTUAL, A. C. Responsabilidade ambiental e esfera pública na América Latina. In DOMINGUES, J. M. Aproximações à América Latina: desafios contemporâneos. Rio de Janeiro: Civilização Brasileira, 2007. p. 141-166. ISBN 978-85-200-0822-5.

EGLER, P. C. G. Perspectivas de uso no Brasil do processo de Avaliação Ambiental Estratégica. Parcerias Estratégicas, vol, 6, no 11, 2011. [Consultado 20 Setembro 2018]. Disponível em: http://seer.cgee.org.br/index.php/parcerias estrategicas/article/view/166. ISSN 2176-9729.

INSTITUTO BRASILEIRO DO MEIO AMBIENTE E DOS RECURSOS NATURAIS RENOVÁVEIS - IBAMA. Sistema Informatizado de Licenciamento Ambiental Federal. [Consultado 04 Janeiro 2019]. Disponível em: https://servicos.ibama.gov.br/licenciamento/.

INSTITUTO BRASILEIRO DO MEIO AMBIENTE E DOS RECURSOS NATURAIS RENOVÁVEIS - IBAMA. Parecer Técnico no 215/2018-COEXP/CGMAC/DILIC. Atividade de Perfuração Marítima nos Bloco FZA-M-57, FZA-M-86, FZA-M-125, FZA-M-127, Bacia da Foz do Amazonas. [Consultado 04 Janeiro 2019]. Disponível em: https://www.ibama.gov.br/phocadownload/notas/2018/SEI IBAMA\%20-\%203786870\%20\%20Parecer\%20Tecnico.pdf.

MILARÉ, E. Estudo prévio de impacto no Brasil. In AB'SABER, A. N.; MÜLLER-PLATEBERG, C. (Org.). Previsão de impactos. 2a ed. São Paulo: USP, 2006. p. 51-80. ISBN 978-85-314-0260-9.

MILARÉ, L. T. O Licenciamento Ambiental: Contribuições para um marco legislativo à luz do pacto federativo ecológico instituído pela Lei Complementar 140/2011. Tese (Doutorado em Direito das Relações Sociais) Pontifícia Universidade Católica de São Paulo, 2016. 
ORGANIZAÇÃO DE COOPERAÇÃO E DESENVOLVIMENTO ECONÔMICO - OCDE. Aplicação da Avaliação Ambiental Estratégica: Guia de Boas Práticas na Cooperação para o Desenvolvimento. Paris: OECD, 2012. [Consultado 12 Outubro 2018]. Disponível em: https://dx.doi.org/10.1787/9789264175877-pt. ISBN 978-9264-17587-7.

PELLIN, A. et al. Avaliação Ambiental Estratégica no Brasil: considerações a respeito do papel das agências multilaterais de desenvolvimento. Revista Engenharia Sanitária e Ambiental, v. 16 n. 1, jan/mar 2011. p. 27-36. [Consultado 10 Dezembro 2019]. Disponível em: http://dx.doi.org/10.1590/S1413-41522011000100006. ISSN 1413-4152.

RIBEIRO, J. C. J. O Que é Licenciamento Ambiental. In RIBEIRO, J. C. J. (Org.). Licenciamento Ambiental: Herói, Vilão ou Vítima. Belo Horizonte: Arraes Editores, 2015. p. 02-26. ISBN 978-85-8238-153-3.

RIBEIRO, J. C. J.; MOTA, M. L. R. O Significativo Impacto Ambiental. In RIBEIRO, J. C. J. (Org.). Licenciamento Ambiental: Herói, Vilão ou Vítima. Belo Horizonte: Arraes Editores, 2015. p. 42-50. ISBN 978-85-8238-153-3.

SÁNCHEZ, L. E. Por que não avança a avaliação ambiental estratégica no Brasil? Estudos Avançados, vol. 31, n. 89, São Paulo, jan./apr., 2017. [Consultado 04 Dezembro 2019]. Disponível em: http://dx.doi.org/10.1590/s0103-40142017.31890015. ISSN 1806-9592.

SERRA, C. Tragédia em Mariana: a história do maior desastre ambiental do Brasil. Rio de Janeiro: Record, 2018. ISBN 978-85-01-11573-7.

SOUSA, J. A. S. O Programa de Zoneamento Ecológico-Econômico para a Amazônia Legal e a sustentabilidade: aspirações e realidades. Tese (Doutorado em Desenvolvimento Sustentável) - Centro de Desenvolvimento Sustentável. Universidade de Brasília, 2008.

THEODORO, S. H.; BARROS, J, G. C.. Política Nacional do Meio Ambiente: conquistas e perspectivas. In THEODORO, S. H. (org.). Os 30 anos da Política Nacional de Meio Ambiente: conquistas e perspectivas. Rio de Janeiro: Editora Garamond, 2011. ISBN 978-85-76-17244-4. 